\title{
Identification of High Yielding Tropical Strawberry Genotypes by Assessment of Yield Attributing Traits under Field Condition
}

\author{
Mahmuda Akter ${ }^{\circledR}$ \\ Mofazzal Hossain ${ }^{2}$ \\ Azizul Haque ${ }^{3}$ \\ Nasrin Akter Ivy ${ }^{4}$
}

Director Research Office, Bangabandhu Sheikh Mujibur Rahman Agricultural University, Gazipur, Bangladesh ${ }_{2,3}$ Department of Horticulture, Bangabandhu Sheikh Mujibur Rahman Agricultural University, Gazipur, Bangladesh

'Department of Genetics and Plant Breeding, Bangabandhu Sheikh Mujibur Rahman Agricultural University, Gazipur, Bangladesh

\begin{abstract}
In this study, eight different genotypes namely FA-006, FA-007, FA-008, FA-015, FA-016, FA017, FA-022 and BARI Strawberry-1 were grown under field condition to evaluate the superior performance of tropical strawberry genotypes in terms of their morphological characters. Our results revealed that FA-015 genotype showed better performance in terms of plant height, leaf number, canopy spread, flowers plant-1, fruit set compared to other genotypes. The maximum days (62.29) required for flower initiation was found in the genotype FA-007 while the minimum days (30.59) required for flower initiation was recorded in the genotype FA-016. As regards to the fruit characters (length, width and weight), FA-022 genotype exhibited highest performances compared to other genotypes. Our results also implied that the highest fruit yield plant-1 $(213.8 \mathrm{~g})$ was obtained from the genotype FA-022 and the highest amount of TSS (10.71\%) was found in the genotype BARI Strawberry-1. Genotype FA-015 was superior in respect of growth related parameters and genotype FA-022 found potential in terms of fruit yield. Further research is needed on molecular characterization and marker aided selection of strawberry genotypes.
\end{abstract}

Keywords: Morphological characters, Growth characters, Strawberry genotypes, Fruits quality and Yield.

\section{Introduction}

The strawberry, scientifically known as Fragaria ananassa, belongs to Rosaceae family. The cultivated strawberry, Fragaria $\times$ ananassa, is a cross between two wild strawberries: Fragaria virginiana and Fragaria chiloensis. The strawberry is mainly cultivated for its characteristics juicy fruit. It is widely grown fruit crop in the world and adapted in geographically diverse area [1].

There are more than 20 Fragaria species and numerous cultivars commercially cultivated in several countries [2]. The cultivars vary remarkably in morphological characters [3]. Different genotypes have different genetic potential. The genotypic and phenotypic interaction of strawberry plant is highly cultivar dependent. Therefore, the choice of a cultivar is of paramount importance for successful strawberry cultivation [4]. A germplasm collection with good variability for the desirable characters is the basic requirement of any crop improvement program [5]; [6]. In addition, crop improvement is primarily based on extensive evaluation of germplasm. Morphological characters of a plant are most important for understanding nature as well as yield of a crop. Yield of strawberry is not possible only due to climatic factors, it also cultivar dependent. Early fruit bearing, early flower initiation, more number of fruit set, runner production, fruit weight, size and shape etc. are inherent characters; all of these contribute to yield.

In Bangladesh, only a few varieties of strawberry are being cultivated, besides there are some other genotypes too; which have higher yield potential compared to the released varieties. To cultivate strawberry in Bangladesh, research on selection of appropriate genotypes in respect of their growth related parameters, assessment of flower and fruit characteristics are the prerequisite for its commercial cultivation. Considering the above facts and constraints, the present study was conducted to find out the high yielding genotypes in terms of their yield and yield contributing morphological traits.

\section{Materials and Methods}

\subsection{Experimental Site}

The experiment was conducted at the Horticultural Research Farm of Bangabandhu Sheikh Mujibur Rahman Agricultural University, Gazipur during the period from November, 2014 to April, 2015. The experimental site is 
located at the $24.09^{\circ} \mathrm{N}$ latitude and $90.26^{\circ} \mathrm{E}$ longitudes and 8.5 meter above the sea level. The area represents the Madhupur Tract under Agro Ecological Zone (AEZ) 28.

\subsection{Climate and Soil}

The experimental site was situated in the subtropical climatic zone characterized by three distinct seasons; the monsoon or rainy season (May to October), the winter or dry season (November to February) and the pre-monsoon or hot season (March to April). The mean annual rainfall of the area is about $2200 \mathrm{~mm}$ but its distribution is uneven. The experimental area was located in medium high land. The soil was Clay loam in texture having a $\mathrm{P}^{\mathrm{H}}$ of 6.2.

\subsection{Experimental Design and Layout}

The field experiment was laid out in Randomized Complete Block Design (RCBD) with three replications. The genotypes were treated as treatments. Each block consisted of 8 plots and the dimension of each plot was $1 \mathrm{~m} \times$ $2.0 \mathrm{~m}$. Total number of plot was 24 . The plant to plant spacing was $60 \mathrm{~cm}$ and row to row spacing was $50 \mathrm{~cm}$. The planting materials (genotypes) were collected from different sources (Table 1).

\subsection{Intercultural Operation}

Seedlings were planted on 20 November 2014. Runners were removed at every 3 to 4 days intervals in order to make the shoot tip capable to initiate flower. Straw mulch was applied around the plants as a normal practice in order to conserve soil moisture, decreasing weed growth and to provide healthy condition for the fruits. Irrigation was given whenever necessary to keep the soil moisture. Netting was done to protect strawberry from birds, especially doves; sparrow and parrots cause losses to strawberry at the time of berry ripening. All other necessary cultural practices and plant protection measures were followed uniformly for all the plots and treatments during the entire period of experimentation. Fruits were harvested by hand picking at ripening stage when three-fourths portion of the fruit skin attained red color at an interval of 3 to 4 days and handled very carefully.

\subsection{Harvesting}

Harvesting was done early in the day while temperatures were cool. Immediately after harvest, strawberries were sorted to eliminate damaged fruit, and selected for uniform size and color for collecting data.

\subsection{Data Collection and Analysis}

The following qualitative characters such as foliage density, leaf color, fruit color and shape were recorded by close observation according to the descriptors for strawberry [7]. On the other hand, plant height (cm), leaves plant $^{-1}$, canopy spread $(\mathrm{cm})$, runners plant ${ }^{-1}$, days to flower initiation, flower plant ${ }^{-1}$, fruit plant ${ }^{-1}$, weight of individual fruit $(\mathrm{g})$, fruit length $(\mathrm{cm})$, fruit width $(\mathrm{cm})$, fruit yield ${ }^{-1}(\mathrm{~g})$ and total soluble solids $(\%)$ were recorded for quantitative characters. Data of different quantitative parameters were pooled and analyzed, following RCB design using MSTAT-C program. The mean comparison was done following the Duncan's Multiple Range Test (DMRT).

\section{Results and Discussion}

\subsection{Plant Height, Leaves Plant ${ }^{-1}$ Canopy Spread and Runners' Plant ${ }^{1}$}

Significant variation among the germplasm was observed for plant height, leaves plant ${ }^{-1}$, canopy spread $(\mathrm{cm})$ and runners plant ${ }^{-1}$ (Table 2$)$. The tallest plant $(24.50 \mathrm{~cm})$ was recorded in the genotype $\mathrm{FA}-015$ and the shortest plant $(14.98 \mathrm{~cm})$ was recorded in the genotype BARI Strawberry-1 which was statistically identical with the genotype FA-017 $(15.85 \mathrm{~cm})$. Rahman, et al. [8] found that the tallest plant was $25.00 \mathrm{~cm}$ and the shortest plant was $14.67 \mathrm{~cm}$ which support the present findings. The maximum number of leaves plant ${ }^{-1}(51.80)$ was recorded in the genotype FA-015 whereas the minimum number of leaves plant ${ }^{-1}$ (11.59) was obtained from the genotype FA007 which was statistically identical with the genotypes FA-006 $(13.42 \mathrm{~cm})$ and FA-017 $(12.87 \mathrm{~cm})$. Canopy spread was significantly influenced by different genotypes (Table 1). The maximum $(44.67 \mathrm{~cm})$ canopy spread was observed in the genotype FA-015 and the minimum $(18.67 \mathrm{~cm})$ canopy spread was found in the genotype FA-017 which was statistically identical with the genotype BARI Strawberry-1 $(19.00 \mathrm{~cm})$. The maximum number of runners was found in the genotype FA-008 (6.43) followed by the genotype FA-007 (5.40), whereas the minimum number of runners per plant was found in the genotype FA-015 (2.30) which was statistically identical with the genotype FA-016 (2.44). The genotypes FA-006, FA-022 and BARI Strawberry-1 were statistically identical which produced moderate number of runners.

\subsection{Foliage Density and Leaf Color}

Foliage density and color of leaf varies among the genotypes (Table 3). Foliage density of different strawberry genotypes was classified into three classes namely: dense, intermediate and spare. Among the genotypes FA-006, FA-007, FA-016, FA-017 showed dense; genotypes FA-015 and BARI Strawberry-1 showed intermediate and rest of the genotypes FA-008 and FA-022 showed sparse foliage density. Leaf color of different strawberry genotypes was classified into three colors. The leaves of the genotypes FA-008, FA-015 and BARI Strawberry-1 were dark in color; genotype FA-022 was intermediate in leaf color and leaf of rest genotypes FA-006, FA-007, FA-016, FA-017 were light colored (Fig. 1 and Table 3).

\subsection{Days to Flower Initiation and Flowers Plant}

Days to flower initiation and flowers plant ${ }^{-1}$ differed significantly among the genotypes (Table 4). The maximum days were required for flower initiation by the genotype FA-007 (68.20). The minimum days to flower initiation was recorded in the genotype FA-016 (30.59) which was statistically identical with the genotype FA-017 (33.84). It is in agreement with the findings of Riyaphan, et al. [9] who recorded that number of days from transplanting to first blooming ranged from 67.50 to 78.90 in cv. 'Tioga' and from 40.80 to 47.23 in cv. 
'Tochiotome'. The maximum number of flowers plant ${ }^{-1}$ (20.11) was recorded in the genotype FA-015 which was statistically identical with the genotype FA-016 (18.74). The minimum number of flowers plant-1 was produced by the genotype FA-008 (10.29) which was statistically identical with the genotypes FA-007, FA-022 and BARI Strawberry-1.

\subsection{Fruit Plant, ${ }^{1}$ Fruit Length, Fruit Width, Weight of Individual Fruit and Brix (\%)}

Significance variation was recorded in different fruit characteristics (Table 5). The highest number of fruit plant $^{-1}$ (14.67) was observed in the genotype FA-015 which was statistically identical with the genotypes FA-016 (14.17) and FA-006 (12.46). The lowest number of fruit plant ${ }^{-1}$ (7.14) was recorded in the genotype FA-022 which was statistically identical with the genotypes FA-007, FA-008, FA-017 and BARI Strawberry-1. Rahman and Ahmad $[10]$ reported that fruit per plant in fifteen strawberry lines were between 4 to 27 ; which more or less supported the above finding. The maximum fruit length $(5.24 \mathrm{~cm})$ was recorded in the genotype FA-022 and the minimum fruit length $(2.54 \mathrm{~cm})$ was recorded in the genotype FA-008 which was statistically identical with the genotype FA-015 $(2.61 \mathrm{~cm})$. The highest fruit width was recorded in the genotype FA-022 $(3.35 \mathrm{~cm})$ which were statistically identical with the genotypes FA-007 $(3.14 \mathrm{~cm})$, FA-006 $(3.10 \mathrm{~cm})$ and FA-017 $(3.05 \mathrm{~cm})$. The lowest fruit width was recorded in the genotype FA-015 $(2.13 \mathrm{~cm})$ which were statistically identical with the genotypes FA-008 $(2.32 \mathrm{~cm})$ and BARI Strawberry-1 $(2.95 \mathrm{~cm})$. The maximum fruit weight $(18.13 \mathrm{~g})$ was found in the genotype FA-006 which was statistically identical with the genotypes FA-007 (17.11g), FA-017 (17.87g) and FAO22 (16.24g). The minimum fruit weight $(6.49 \mathrm{~g})$ was recorded in the genotypes FA-008 (6.93g) and FA-015 (6.49g) which were statistically identical. Among the genotypes, genotype BARI Strawberry-1 contained the highest amount of TSS (10.71\%) followed by the genotype FA-008 (9.40\%). The lowest TSS was exhibited by the genotypes FA-016 (5.84\%) and FA-006 (6.02\%) which were statistically identical. Capocasa, et al. [11] found that TSS of strawberry fruits varied significantly and ranged from $5.8 \%$ to $9.7 \%$.

\subsection{Fruit Shape and Fruit Color}

Fruit shape and color varies significantly among the genotypes (Table 6). Fruit shape of different strawberry genotypes was classified into 6 shapes. The fruits of the genotype FA-008 and BARI Strawberry-1were conical shaped.While the fruit of the genotypes FA-007 and FA- 017 were long conical shaped. The fruit of the genotypes FA-006 and FA-016 were wedged shaped. On the other hand the fruit of the genotype FA-022 was oblate shaped and the genotype FA-015 was round shaped. The fruit of the genotype FA-022 was light colored. Color of fruits of different strawberry genotypes was classified into light, intermediate, dark and very dark category. While the fruit of the genotypes FA-008 and FA-015 were intermediate in color, the genotype BARI Strawberry-1, FA-006 and FA-016 had dark colored fruit and the genotypes FA-007 and FA-017 had very dark colored fruits (Fig. 2 and Table 6).

\subsection{Fruit Tield Plant ${ }^{1}$}

The genotypes significantly influenced fruit yield plant-1 (Fig. 3). The maximum fruit yield plant ${ }^{-1}(213.80 g)$ was recorded in the genotype FA-022 followed by the genotype FA-016 (173.7g). The minimum fruit yield plant ${ }^{-1}$ was recorded in the genotype FA-017 (94.5g) followed by the genotype FA-006 (102.6g). Rahman and Ahmad [10] found that yield per plant in fifteen strawberry lines were between $58 \mathrm{~g}$ to $85 \mathrm{~g}$.

\section{Conclusion}

Our present findings revealed that, genotype FA-015 was superior in respect of growth related parameters and genotype FA-022 found potential in terms of fruit yield. Regarding potential filed performance, FA-015 and FA022 could be utilized in future breeding program.

\section{References}

[1] M. K. Biswas, M. Dutt, U. K. Roy, R. Islam, and M. Hossain, "Development and evaluation of in vitro somaclonal variation in strawberry for improved horticultural traits," Scientia Horticulturae, vol. 122, pp. 409-416, 2009.

R. M. Gaafar and M. M. Saker, "Monitoring of cultivars identity and genetic stability in strawberry varieties grown in Egypt," World Journal of Agricultural Science, vol. 2, pp. 29-36, 2006.

[3] G. C. Biswas, M. A. Uddin, and M. S. Akhter, "Regional yield trial of strawberry," Research Report on Horticultural Crops. BARI, Joydebpur, Gazipur-17012010.

[4] R. Asrey and R. Singh, "Evaluation of strawberry varieties under semi-arid irrigated region in Punjab," Indian Journal of Horticulture, vol. 61, pp. 122-124, 2004.

[5] D. L. Singhania, D. Singh, and R. S. Raje, "Advances in spices and achievements of spices research in India," Agrobios, Agro House,Chopasani Road, Jodhpur, vol. 342002, pp. 678-695, 2006.

[6] AVRDC, Training manual on vegetable production. Shanhua, Tainan, Taiwan: Asian Vegetable Research and Development Centre (AVRDC), 1990.

IBPGR, IBPGR programme structure. Rome, Italy: International Board for Plant Genetic Resources, 1986.

[8] M. M. Rahman, M. M. Rahman, M. M. Hossain, M. A. K. Mian, and Q. A. Khaliq, "Characterization and field performance of 15 strawberry germplasm under Bangladesh condition," SAARC Journal of Agriculture, vol. 11, pp. 81-94, 2013.

[9] P. Riyaphan, N. Pipattanawong, and S. Subhadrabandu, "Influence of different climatic conditions on growth and yield of strawberry plants in Thailand. In: Production technology for low-chill temperate fruits. A. P. George and U. Boonprakob (Ed.)," ACIAR Technical Report2005.

[10] M. M. Rahman and M. R. Ahmad, "Collection and evaluation of strawberry lines," Research Report on Horticultural Crops, BARI, Joydebpur, Gazipur-17012010.

[11] F. Capocasa, J. Scalzo, B. Mezzetti, and M. Battino, "Combining quality and antioxidant attributes in the strawberry: The role of genotype," Food Chemistry, vol. 111, pp. 872-878, 2008. 

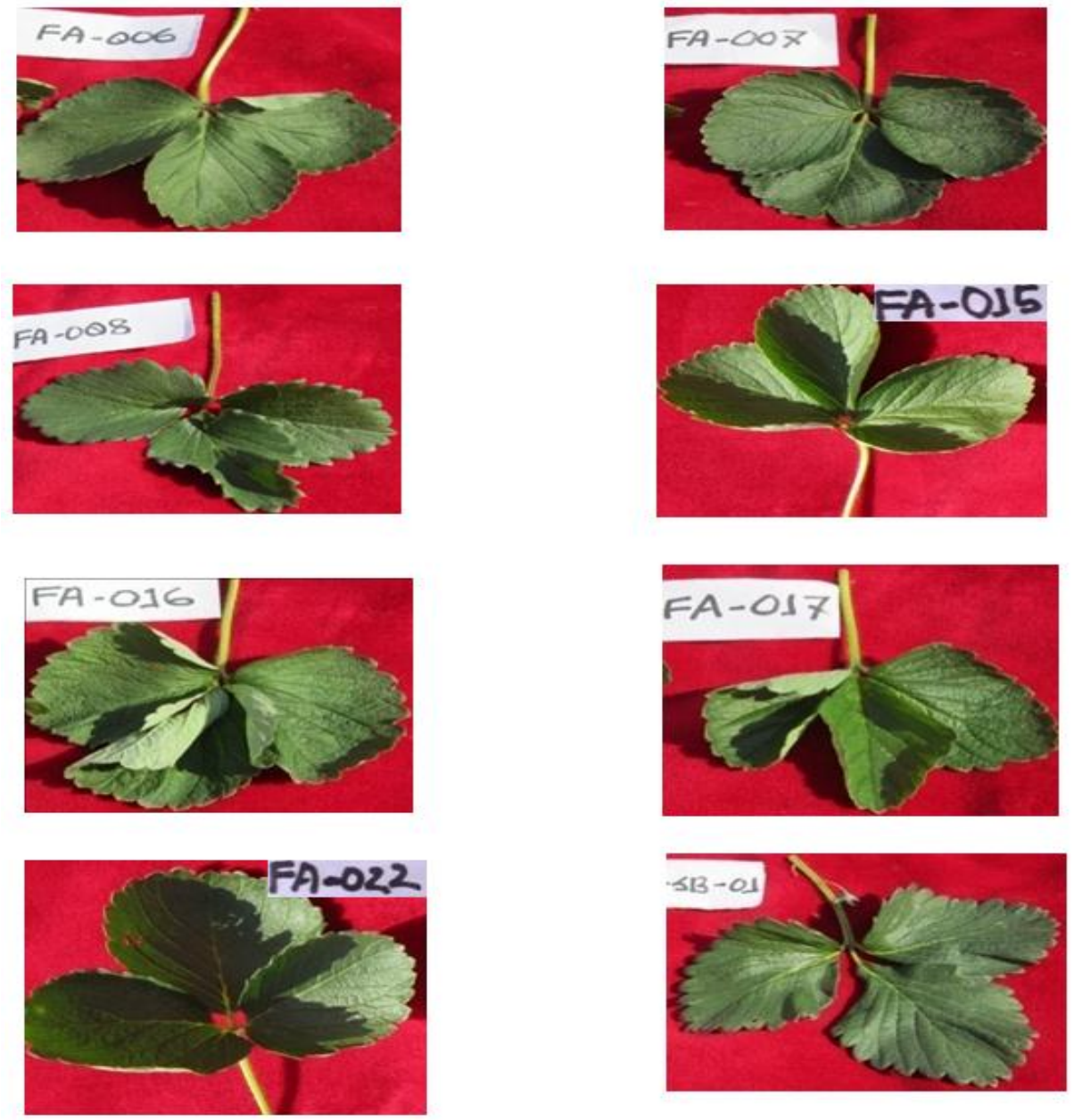

Fig-1. Leaf characteristics of eight strawberry genotypes
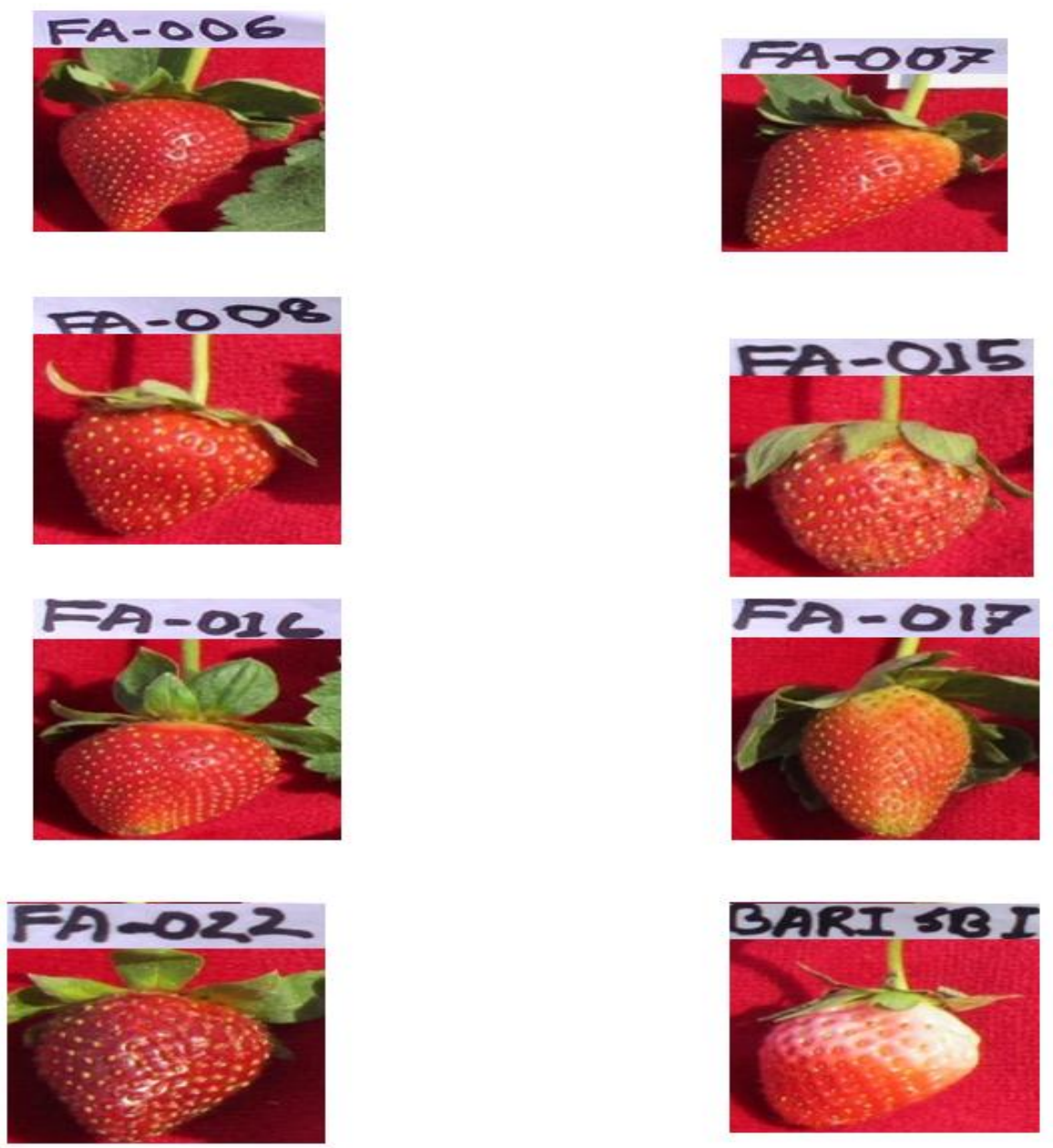

Fig-2. Fruit characteristics of eight strawberry genotypes 


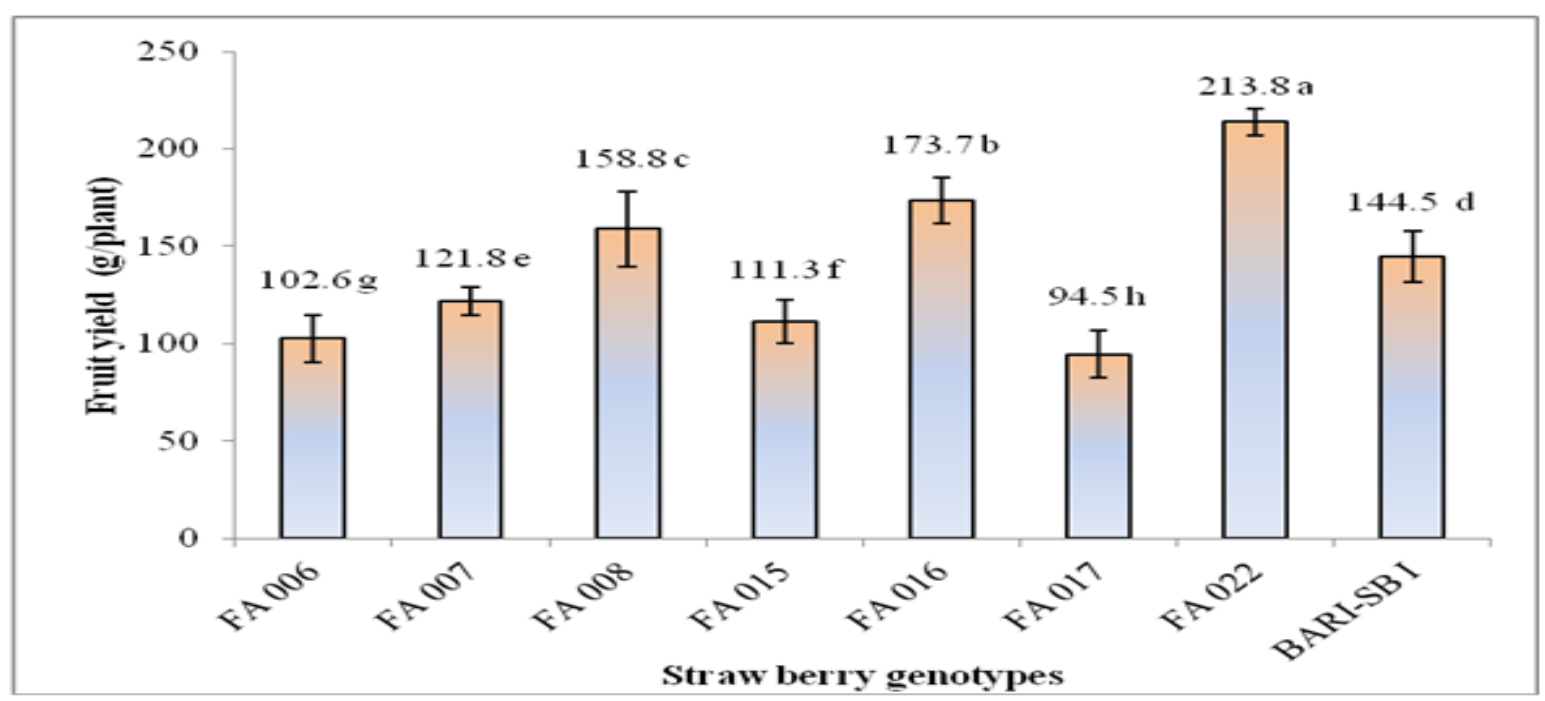

Fig-3. Fruit yield (g/plant) of eight strawberry genotypes. Means bearing different letter(s) in a column differ significantly by DMRT at $1 \%$ level

Table-1. Sources of planting materials

\begin{tabular}{l|l|l}
\hline Accession no. & Name of variety & Country of origin \\
\hline FA-006 & Rabi-1 & Japan \\
\hline FA-007 & Rabi-2 & Japan \\
\hline FA-008 & Rabi-3 & Japan \\
\hline FA-015 & Camarosa & USA \\
\hline FA-016 & California-1 & USA \\
\hline FA-017 & California-2 & USA \\
\hline FA-022 & California-3 & USA \\
\hline BARI released variety & BARI Strawberry-1 & Bangladesh \\
\hline
\end{tabular}

Table-2. Growth characteristics of eight strawberry genotypes

\begin{tabular}{l|c|l|c|c}
\hline Genotypes & $\begin{array}{l}\text { Plant height } \\
(\mathbf{c m})\end{array}$ & Leaves plant & $\begin{array}{c}\text { Canopy spread } \\
(\mathbf{c m})\end{array}$ & Runners plant $^{-1}$ \\
\hline FA-006 & $20.13 \mathrm{bc}$ & $13.42 \mathrm{bc}$ & $26.67 \mathrm{bcd}$ & $3.16 \mathrm{~d}$ \\
\hline FA-007 & $21.15 \mathrm{~b}$ & $11.59 \mathrm{c}$ & $25.67 \mathrm{~cd}$ & $5.40 \mathrm{~b}$ \\
\hline FA-008 & $22.10 \mathrm{~b}$ & $14.88 \mathrm{~b}$ & $28.33 \mathrm{bc}$ & $6.43 \mathrm{a}$ \\
\hline FA-015 & $24.50 \mathrm{a}$ & $51.80 \mathrm{a}$ & $44.67 \mathrm{a}$ & $2.30 \mathrm{e}$ \\
\hline FA-016 & $18.00 \mathrm{~cd}$ & $15.56 \mathrm{~b}$ & $23.67 \mathrm{~d}$ & $2.44 \mathrm{e}$ \\
\hline FA-017 & $15.85 \mathrm{de}$ & $12.87 \mathrm{bc}$ & $18.67 \mathrm{e}$ & $4.36 \mathrm{c}$ \\
\hline FA-022 & $21.29 \mathrm{~b}$ & $14.44 \mathrm{~b}$ & $29.00 \mathrm{~b}$ & $3.68 \mathrm{~d}$ \\
\hline BARI SB-1 & $14.98 \mathrm{e}$ & $14.26 \mathrm{~b}$ & $19.00 \mathrm{e}$ & $3.59 \mathrm{~d}$ \\
\hline Level of significance & $* *$ & $*$ & $* *$ & $* 6.08$ \\
\hline CV $\%)$ & 6.95 & 9.64 & 6.18 & $3.2 \%$ \\
\hline
\end{tabular}

Means bearing same letter(s) in a column do not differ significantly by DMRT. ${ }^{*} *$ Significant at $1 \%$ and $*$ Significant at $5 \%$ level.

Table-3. Foliage density and leaf color of eight strawberry genotypes

\begin{tabular}{l|l|l}
\hline Genotypes & Density of foliage & Colour of leaf \\
\hline FA-006 & Dense & Light \\
\hline FA-007 & Dense & Light \\
\hline FA-008 & Sparse & Dark \\
\hline FA-0015 & Intermediate & Dark \\
\hline FA-016 & Dense & Light \\
\hline FA-017 & Dense & Light \\
\hline FA-022 & Sparse & Intermediate \\
\hline BARI SB-1 & Intermediate & Dark \\
\hline
\end{tabular}

Table-4. Floral characteristics of eight strawberry genotypes

\begin{tabular}{l|c|c}
\hline Genotypes & Flower initiation (Days) & Flowers plant $^{-1}$ \\
\hline FA-006 & $48.04 \mathrm{~d}$ & $14.65 \mathrm{bc}$ \\
\hline FA-007 & $68.20 \mathrm{a}$ & $12.96 \mathrm{~cd}$ \\
\hline FA-008 & $62.97 \mathrm{~b}$ & $10.29 \mathrm{~d}$ \\
\hline FA-015 & $53.59 \mathrm{c}$ & $20.11 \mathrm{a}$ \\
\hline FA-016 & $30.59 \mathrm{f}$ & $18.74 \mathrm{ab}$ \\
\hline FA-017 & $33.84 \mathrm{f}$ & $14.88 \mathrm{bc}$ \\
\hline FA-022 & $44.49 \mathrm{e}$ & $11.00 \mathrm{~cd}$ \\
\hline BARI SB-1 & $42.38 \mathrm{e}$ & $13.54 \mathrm{~cd}$ \\
\hline Level of significance & $* *$ & $* *$ \\
\hline CV (\%) & 4.08 & 16.63 \\
\hline \multicolumn{2}{l}{ Means bearing same letter(s) in a column do not differ significantly by DMRT. ** Significant at $1 \%$ and * }
\end{tabular}

Means bearing same letter(s) in a column do not differ significantly by DMRT. ${ }^{*}$. Significant at $1 \%$ and * Significant at $5 \%$ level. 
Table-5. Fruit characteristics of eight strawberry genotypes

\begin{tabular}{|c|c|c|c|c|c|}
\hline Genotypes & Fruit/plant & $\begin{array}{l}\text { Fruit length } \\
(\mathrm{cm})\end{array}$ & $\begin{array}{l}\text { Fruit width } \\
(\mathrm{cm})\end{array}$ & $\begin{array}{l}\text { Individual } \\
\text { fruit wt. (g) }\end{array}$ & Brix (\%) \\
\hline$\overline{\mathrm{FA}-006}$ & $12.46 \mathrm{ab}$ & $4.11 \mathrm{bc}$ & $3.10 \mathrm{ab}$ & $16.24 \mathrm{ab}$ & $6.02 \mathrm{ef}$ \\
\hline FA-007 & $8.47 \mathrm{c}$ & $4.22 \mathrm{~b}$ & $3.14 \mathrm{ab}$ & $17.11 \mathrm{ab}$ & $6.16 \mathrm{e}$ \\
\hline FA-008 & $8.52 \mathrm{c}$ & $2.54 \mathrm{~d}$ & $2.32 \mathrm{c}$ & $6.93 \mathrm{~d}$ & $9.40 \mathrm{~b}$ \\
\hline FA-015 & $14.67 \mathrm{a}$ & $2.61 \mathrm{~d}$ & $2.13 \mathrm{c}$ & $6.49 \mathrm{~d}$ & $7.92 \mathrm{c}$ \\
\hline FA-016 & $14.17 \mathrm{a}$ & $3.91 \mathrm{c}$ & $3.00 \mathrm{~b}$ & $13.2 \mathrm{Oc}$ & $5.84 \mathrm{f}$ \\
\hline FA-017 & $8.27 \mathrm{c}$ & $4.00 \mathrm{bc}$ & $3.05 \mathrm{ab}$ & $17.87 \mathrm{ab}$ & $6.97 \mathrm{~d}$ \\
\hline FA-022 & $7.14 \mathrm{c}$ & $5.24 \mathrm{a}$ & $3.35 \mathrm{a}$ & $18.13 \mathrm{a}$ & $7.92 \mathrm{c}$ \\
\hline BARI SB-1 & $10.68 \mathrm{bc}$ & $3.87 \mathrm{c}$ & $2.95 \mathrm{~b}$ & $16.11 \mathrm{~b}$ & $10.71 \mathrm{a}$ \\
\hline Level of significance & *** & $*$ & *** & *** & *** \\
\hline $\mathrm{CV}(\%)$ & 17.45 & 4.16 & 6.02 & 7.50 & 1.84 \\
\hline
\end{tabular}

Means bearing same letter(s) in a column do not differ significantly by DMRT. ** Significant at $1 \%$ and $*$ Significant at $5 \%$ level.

Table-6. Fruit shape and color of strawberry genotypes

\begin{tabular}{l|l|l}
\hline Genotypes & Shape of fruits & Color of fruits \\
\hline FA-006 & Wedged & Dark \\
\hline FA-007 & Long Conic & Very dark \\
\hline FA-008 & Conical & Intermediate \\
\hline FA-015 & Round & Intermediate \\
\hline FA-016 & Wedged & Dark \\
\hline FA-017 & Long Conic & Very dark \\
\hline FA-022 & Oblate & Light \\
\hline BARI SB-1 & Conical & Dark \\
\hline
\end{tabular}

Citation | Mahmuda Akter; Mofazzal Hossain; Azizul Haque; Nasrin Akter Ivy (2016). Identification of High Yielding Tropical Strawberry Genotypes by Assessment of Yield Attributing Traits under Field Condition. Agricultural Development, 2: 22-27.

History:

Received: 6 March 2017

Revised: 11 May 2017

Accepted: 25 May 2017

Published: 1 June 2017

Licensed: This work is licensed under a Creative Commons

Attribution 3.0 License $(\mathrm{cc})$

Publisher: Eastern Centre of Science and Education
Acknowledgement: The author's are grateful to Md. Nurealam Siddiqui, Assistant Professor, Department of Biochemistry and Molecular Biology, Bangabandhu Sheikh Mujibur Rahman Agricultural University, Gazipur 1706, Bangladesh for assisting in statistical analysis.

Funding: This research was supported by the Ministry of Science and Technology, People's Republic of Bangladesh for their financial support.

Competing Interests: The authors declare that they have no conflict of interests.

Transparency: The authors confirm that the manuscript is an honest, accurate, and transparent account of the study was reported; that no vital features of the study have been omitted; and that any discrepancies from the study as planned have been explained.

Ethical: This study follows all ethical practices during writing.

Eastern Centre of Science and Education is not responsible or answerable for any loss, damage or liability, etc. caused in relation to/arising out of the use of the content. Any queries should be directed to the corresponding author of the article. 